\title{
PROBLEMAS DE UM SERVIÇO DE ENFERMAGEM - Experiência na estruturação de um programa de trabalho
}

\author{
Dilma Neto de Menezes1, Maria do Carmo Santos Lopes 1
}

MENEZES, D. N. \& LOPES, M. C. S. Problemas de um serviço de enfermagem; experiência na extruturação de um programa de trabalho. Rev. Bras. Enf., Brasilia, 39 (2/3): $21-25$, abr./set., 1986.

\begin{abstract}
RESUMO. O trabalho foi desenvolvido visando identificar problemas e analisar sugestões que servissem de subsídios para estruturação de um programa de atjvidades centrado nas necessidades sentidas pelos enfermeiros, estabelecendo estragégias e ações que possibilitem mudanças na prática da Enfermagem no hospital em estudo.
\end{abstract}

ABSTRACT. The main objective of this work, was to identify and analyse suggestions that can to be utilized for a structuration to the nurses need perceived, establishing strategies and actions that can change the Nursing practice in the hospital studied.

\section{INTRODUÇÃO}

As experiências profissionais em assistência de enfermagem direta ao paciente e nos diversos níveis de liderança, desempenhando chefia de Serviços de Enfermagem, despertaram a preocupação com a necessidade de efetuar a análise dos problemas inerentes à assistência de Enfermagem a nível hospitalar.

$O$ cuidado de enfermagem prestado ao paciente internado nos Hospitais apresenta tão graves deficiências que, ao constatá-las, surgiram questionamentos sobre os fatores que, de maneira favorável ou desfavorável, vêm interferindo na prática da profissão de Enfermagem.

Apraz conhecer os trabalhos cient íficos que, nos últimos anos, têm enriquecido de conhecimentos a ciência da Enfermagem, mas constrange assistir à defasagem da tecnologia em relação ao desenvolvimento das atividades em nossa realidade hospitalar.

O problema assume importância, quando se toma consciência de que a maioria dos enfermeiros não está consciente dos desafios que lhes são impostos nos serviços onde eles têm que assumir os encargos de chefes de equipes de enfermagem e, decorrente disto, os encargos de líderes e de agentes de mudanças.

A enfermagem técnico-científica, no País, surgiu da necessidade de melhorar o nível de Saúde do povo, e parece que antes, como agora, tem-se que estar preparado para a luta de mostrar, a cada dia, os problemas que interferem positiva ou negativamente na atuação da enfermagem, e os quais têm sérias repercussões na assistência ao cliente.

Refletindo sobre o assunto, buscou-se identificar na literatura princípios e referências que servissem de embasamento a esse trabalho e encontrou-se segurança ao constatar a já existência de Princípios Básicos de Enfermagem BRASIL. Ministério da Saúde 3 , da competência das Unidades Prestadoras de Serviços de Enfermagem Hospitalar BRASIL. Ministério da Previdência e Assistência Social4 e da análise dos aspectos relacionados com o papel atual do enfermeiro, seu espaço profissional e dos fatores que influenciam na administração da prática da profissão.

Refletindo sobre o espaço profissional entendido como o lugar de inserção ou de ação social (ANGERAMI \& ALMEIDA ${ }^{1}$ ), pode-se perceber que os limites de atuação do enfermeiro não estão bem definidos, e as fronteiras da profissão são invadidas por elementos de três níveis de formação que, recebendo salários diferentes, é de esperar que desempenhem papéis diferentes.

Observa-se, entretanto, que na prática isto não ocorre, e os de menor preparo são os que permanecem 24 horas jun to aos pacientes, realizando as atividades mais complexas da assistência de Enfermagem.

DOURADO 5 , questionando sobre o papel profissional do enfermeiro no contexto histórico atual, afirma que "a nova enfermeira deverá ser o profissional que estimulará a comunidade para que se ajude a si mesma". Em 1976 o seminário de OPS conclui que "qualquer papel de saúde é resultante de uma complexa inter-relação entre recomendações e expectativas das associações profissionais, órgãos empregadores, usuários, assim como da imagem e expectativas da pessoa que a desempenha".

BARROS \& ARAUJO2 ${ }^{2}$, escrevendo sobre a prática administrativa do enfermeiro, friza que esta é in- 
fluenciada pelas necessidades da comunidade na qual ela opera, e que a administração pode ser conceituada como o processo pelo qual o enfermeiro organiza e dirige as atividades de enfermagem. Os insumos básicos decorrentes de recursos humanos e materiais necessários ao dese mpenho administrativo e à boa prática da organização dos serviços de Enfermagem, na maioria das Instiuições de Saúde, são carentes e inadequados, e estas dificuldades somam-se ainda aos problemas de relacionamento inter-pessoal e de comunicação entre os elementos da equipe de trabalho.

$\mathrm{O}$ trabalho em equipe multi-profissional surge numa tentativa de mudança, visando somar os esforços dos vários profissionais de saúde. FERNANDES6 afirma que a implantação da filosofia de saúde vem sof rendo interferências que decorrem da luta de alguns profissionais pelo status e compensação financeira, da falta de participação no desenvolvimento social, das relações conflitivas de uma sociedade competitiva onde o jogo do poder impossibilita a prática da cooperação no trabalho, do monopólio de saber utilizado por algumas profissões como instrumento de dominação, e de papel secundário atribuído a profissões predominantemente femininas como é o caso da enfermagem.

Desempenhando chefia de Serviço de Enfermagem em uma Instituição Hospital do INAMPS, buscou-se, após estudo dos aspectos abordados, identificar problemas e analisar sugestões que servissem de subsídios para estruturação de um programa de trabalho, centrado em necessidades visualizadas pelos autores e pelo grupo de enfermeiros do Hospital, estabelecendo estratégias e ações com vistas à realização de mudanças na prática da Enfermagem desenvolvida no Serviço.

\section{OBJETIVOS}

- Identificar os problemas que interferem de maneira negativa na atuação do enfermeiro no Hospital com relação a:

- estrutura física

- estrutura funcional

- pessoal da equipe multi-profissional

- pessoal auxiliar.

- Efetuar um estudo comparativo dos aspectos visualizados pela chefia de enfermagem com os problemas identificados pelos enfermeiros do Serviço.

- Estabelecer um programa de trabalho baseado na análise dos problemas identificados e nas sugestões apresentadas pela chefia e pelos enfermeiros do Hospital.

\section{METODOLOGIA}

Para realização desse trabalho, efetuou-se um levantamento de dados, que foi feito por meio da observação direta, entrevistas pessoais, reuniões com Chefias e pessoal das Unidades prèstadoras de assistência, e aplicação de um questionário aos enfermeiros de um Hospital do INAMPS, na Cidade de Recife, no periodo compreendido entre agosto a outubro de 1984.

O questionário utilizado como instrumento para sondagem de opiniões dos enfermeiros, foram uti- lizadas somente as respostas aos itens 03 e 04, as quais atendiam aos objetivos propostos.

Os enfermeiros que constituíram o universo do trabalho formaram um grupo de 50 que representam $67 \%$ do total de enfermeiros da Instituição.

O trabalho de identificação de problemas e sugestões, efe tuado pela Chefia do Serviço, foi realizado com a colaboração das Chefias das cinco Seções que compõem o Serviço de Enfermagem, e ainda obteve apreciação de enfermeiros das Unidades da Emergência e da Internação do Hospital.

\section{PROCEDIMENTOS E RESULTADOS}

O trabalho foi efetuado em etapas como se segue:

1a Etapa - Em outubro de 1984, foi efetuado pela Chefia do Serviço de Enfermagem um levantamento dos principais problemas que af etavam de maneira negativa a atuação do Serviço de Enfermagem e que estavam relacionados com estrutura física, funcional, com a equipe multiprofissional e com o pessoal auxiliar, cujos resultados se encontram no esquema abaixo.

- Problemas que interferem na atuação do Serviço de Enfermagem.

e m relação à estrutura física:

- precário estado de conservação do prédio;

- instalações hidráulica e elétrica danificadas;

- falta de vestiários;

- falta de enfermarias destinadas a tratamento semi-intensivo de pacientes;

- falta de setor destinado ao preparo de hi-

- per-alimentação parenteral;

- falta de proteção nas janelas de enfermarias, para pacientes desorientados;

- falta de setor destinado a arquivo morto de expedientes da Enfermagem.

em relação à estrutura funcional:

- falta de material de consumo;

- deficiente conservação do equipamento e

- instalações em geral;

- limpeza precária;

- focos de insetos e roedores;

- impressos e expedientes em desordem nas

- enfermarias e salas de chefias;

- pessoal trabalhando sem uniforme e sem identificação;

- visitantes circulando, e religiosos fazendo

- pregação nas enfermarias;

- fumantes nas diversas áreas do Hospital;

- falta de cumprimento às normas do trabalho em Centro Cirúrgico;

- freqüentes sugestões cirúrgicas;

- anotações incompletas e incorretas nos prontuários;

- falta de organização nos postos de enfermagem;

em relação à equipe multiprofissional:

- comunicação inadequada;

- enfermeiros sobrecarregados com tarefas que não lhes são próprias;

- falta de integração da equipe de trabalho;

- prática assistencial de enfermagem em desacordo com metodologia científica; 
- precárias condições de atendimento ao paciente grave fora da Unidade de Tratamento Intensivo (UTI).

em relação ao pessoal auxiliar:

- qualificação inadequada;
- quantidade insuficiente.

2ạ Etapa - Foram aplicados os questionários aos enfermeiros, cujos resultados encontram-se nas tabelas que se seguem:

TABELA 1 - Opinião dos enfermeiros de um Hospital do INAMPS sobre problemas relacionados com a estrutura física que interferem na atuação do pessoal de enfermagem -1984

\begin{tabular}{l|c|c}
\hline \multicolumn{1}{c|}{ PROBLEMAS } & No & \% \\
\hline Planta física antiquada & 14 & 28 \\
Falta de vestiários e bebedouros & 10 & 20 \\
Má conservação das instalações & 07 & 14 \\
Posto de Enfermagem descentralizado & 06 & 12 \\
Falta de área para expurgo & 02 & 04 \\
Reformas no prédio em funcionamento & 02 & 04 \\
Falta de espaço para lazer dos pacientes & 01 & 02 \\
Em branco & 07 & 14 \\
Outros & 01 & 02 \\
TOAL & 50 & 100 \\
\hline
\end{tabular}

TABELA 2 - Opinião dos enfermeiros de um Hospital do INAMPS sobre problemas relacionados com a estrutura funcional que interferem na atuação do pessoal de enfermagem - 1984

\begin{tabular}{l|c|c}
\hline \multicolumn{1}{c|}{ PROBLEMAS } & No & $\%$ \\
\hline Falta de organização e rotinas & 11 & 22 \\
Comunicação inadequada & 08 & 16 \\
Regime autocrático & 07 & 14 \\
Falta de material & 05 & 10 \\
Serviço de Enfermagem subordinado à Divisão Médica & 05 & 10 \\
Outros & 06 & 12 \\
Em Branco & 08 & 16 \\
TOTAL & 50 & 100 \\
\hline
\end{tabular}

TABELA 3 - Opinião dos enfermeiros de um Hospital do INAMPS sobre problemas relacionados com a equipe multiprofissional que interferem na atuação do pessoal de enfermagem -1984

\begin{tabular}{l|c|c}
\hline \multicolumn{1}{c|}{ PROBLEMAS } & No & $\%$ \\
\hline Falta de integração e relacionamento & 20 & 40 \\
Enfermagem assume atribuições de outros serviços & 07 & 14 \\
Autoritarismo de alguns profissionais & 06 & 12 \\
Falta de cumprimento às normas e rotinas & 04 & 08 \\
Falta de urbanidade e humanização & 02 & 04 \\
Desvalorização de alguns profissionais & 02 & 04 \\
Tudo bem & 02 & 04 \\
Outros & 02 & 04 \\
Em branco & 05 & 10 \\
TOTAL & 50 & 100 \\
\hline
\end{tabular}


TABELA 4 - Opinião dos enfermeiros de um Hospital do INAMPS sobre problemas relacionados com o pessoal auxiliar que interferem na atuação do pessoal de enfermagem - 1984

\begin{tabular}{l|c|c}
\hline \multicolumn{1}{c|}{ PROBLEMAS } & No & \% \\
\hline Necessitam treinamento & 12 & 24 \\
Falta integração na equipe de enfermagem & 09 & 18 \\
Falta de responsabilidade & 06 & 12 \\
Não aceitam ordens e supervisão & 05 & 10 \\
Pessoal desestimulado & 04 & 08 \\
Pessoal desviado de função & 04 & 08 \\
Tudo bem & 02 & 04 \\
Déficit de pessoal & 01 & 02 \\
Falta de assiduidade & 01 & 02 \\
Em branco & 06 & 12 \\
TOTAL & 50 & 100 \\
\hline
\end{tabular}

3ạ Etapa - Comparação dos problemas levantados pela chefia do Serviço e apontados pelos enfermeiros nos questionários, e análise das sugestões apresentadas:

1 - O levantamento de problemas relacionados com a estrutura física da Chefia do Serviço demonstra tendência para observação de detalhes da área física enquanto 14 enfermeiros (28\%) consideram a planta física antiquada e os espaços insuficientes, numa visão que consideramos da maior importância, visto que a construção do Hospital está realmente defasada, para a atual demanda de pacientes e a dinâmica do Serviço, que dispõe de 164 leitos para internação e atende em média 650 casos por dia na Emergência e Ambulatórios.

2 - A falta de vestiários citada pela chefia e por 10 enfermeiros (20\%) denota o desconforto que decorre disto para o pessoal em Serviço.

3 - Há equivalência nas respostas em relação ao precário estado de conservação do prédio e das instalações hidráulicas e elétricas atestando a interferência de problemas gerais na atuação da enfermagem.

4 - A ausência de proteção nos leitos utilizados por pacientes inconscientes e falta de proteção nas janelas de enfermarias onde sâo internados pacientes que merecem vigilância, é um problema identificado pela chefia e evidenciado pelos acidentes já constatados no Serviço.

5 - Nas respostas aos problemas relacionados com a estrutura funcional, nota-se, nas colocações de um grupo de sete enfermeiros $(14 \%)$ e de outro grupo de 05 enfermeiros (10\%), demonstração dos conflitos decorrentes, de status social do profissional na Instituição, nas citações relativas à existência de regime autocrático, subordinação do Serviço de Enfermagem à Divisão Médica e falta de valorização do enfermeiro.

6 - A interferência de dificuldades geradas pela falta de cumprimento às normas e rotinas é enfatizada por 11 enfermeiros (22\%) e focalizada pela chefia, especificamente observada no trabalho do Centro Cirúrgico.

7 - A chefia do Serviço e enfermeiros salientam os problemas decorrentes da falta de atendimento adequado à manutenção do equipamento e provimento de material de consumo.

8 - Foi focalizado pela Chefia a deficiência nas anotações dos prontuários e da falta de utilização do Método Científico na prática da Enfermagem mas não se observa a identificação deste problema por parte dos enfermeiros.

9 - A ausência de áreas destinadas para tratamento aos pacientes em regime semi-intensivo, áreas para fumantes, local para arquivo morto e depósito de material, justificada pela Chefia como causa de desorganização no Serviço, não foi observada pelo grupo de enfermeiros.

10 - As freqüentes suspensões de cirurgia, problema identificado pela Chefia do Serviço, enfatizam uma desorganização que é caracterizada pela seguinte afirmação de um enfermeiro "a estrutura funciona inadequadamente".

11 - Tratando-se de problemas relacionados com o trabalho da equipe multiprofissional, um total de 20 enfermeiros (40\%) dá ênfase às dificuldades de relacionamento inter-pessoal, de comunicação e falta de in tegração entre os elementos da equipe.

12 - A Chefia e 07 enfermeiros (14\%) salientam a deficiência no trabalho de alguns elementos da equipe multi-profissional, sobrecarregando com tarefas diversas o pessoal de enfermagem.

13 - O autoritarismo de alguns profissionais é aspecto visto por $12 \%$ dos enfermeiros, interferindo de maneira negativa no trabalho de equipe multi-profissional.

14 - No que se refere ao pessoal auxiliar, a Chefia cita o déficit de quantidade e a necessidade de melhor qualificação do grupo.

15 - Um total de $24 \%$ dos enfermeiros focaliza a necessidade de treinamento do pessoal auxiliar in cluindo também a falta de integração na equipe de enfermagem.

16 - Observa-se nos questionários que, em média, oito enfermeiros (12\%) deixaram-no em branco, além do que outras respostass são inadequadas originando um questionamento:

- há desinteresse ou desconhecimento por estes profissionais, sobre a importância de um prévio 
diagnóstico da situação para estruturação de um programa de trabalho.

4ạ Etapa - O programa de trabalho foi estruturado para o período de 15 meses, iniciando-se em outubro de 1984 .

\section{OBSERVAÇÕES}

O programa de trabalho foi elaborado para 15 meses abrangendo o último trimestre de 1984 e o exercício de 1985.

$\mathrm{Na}$ coluna colocada à direita do cronograma, observam-se anotações referentes ao andamento dos trabalhos seguindo-se avaliação das atividades realizada em abril de 1985 .

As dificuldades decorrentes da falta de autonomia do Serviço, que são uma constante da administração da Enfermagem no País, vão aos poucos sendo superadas e o desenvolvimento das atividades nos transmite segurança e respeito dos dirigentes do Hospital e dos diversos elementos das equipes de trabalho.

- Nota-se que, à medida que problemas mais simples são solucionados, a atenção e o tempo da Chefia do Serviço podem ser utilizados em atividades programadas de maior alcance com vistas à melhoria da assistência e organização do trabalho.

\section{CONCLUSÃO}

A administração centrada na identificação de problemas e com objetivos establecidos é imprescindível no desempenho de qualquer trabalho.

Constata-se na prática da Enfermagem que estes princípios perdem-se na labuta diária dos enfermeiros, gerando conseqüências indesejáveis, tais como a perda progressiva da autonomia do profissional e a falta de integração na equipe multi-profissional que, face às precariedades de condições em que se desenvolve a prática de profissão nas Instituições de Saúde, resulta em conflitos pessoais, falta de motivação para o trabalho e deficiente desempenho técnico e administrativo.

Os fatores externos deficitários, os problemas gerais referentes aos insumos básicos indispensáveis ao trabalho, absorvem a atenção dos enfermeiros, reduzindo seu tempo e incentivo para aquisição de conhecimentos e, mantendo-se em nível de trabalho quase empírico, perdem a visão para estabelecer metas, com vistas à melhoria do padrão assistencial, baseando seu trabalho em rotinas incompatíveis com os ensinamentos recebidos a nível acadêmico.

\section{SUGESTÕES}

Pelo exposto neste trabalho, considera-se que as seguintes sugestões deverão ser consideradas pelos enfermeiros na prática administrativa:

1 - as dificuldades decorrentes das condições precárias de funcionamento das Instituições não devem conseguir fazer sombra aos anseios de mudança e à capacidade inovadora dos profissionais de enfermagem;

2 - os problemas devem ser identificados pelos enfermeiros sempre que se disponham a iniciar um trabalho numa Unidade Assistencial;

3 - a capacitação dos enfermeiros para estabelecer diagnóstico da situação deve ser estimulada a partir das Instituições de Ensino;

4 - as diferenças individuais e a diferença de valores devem ser reconhecidas e aceitas pelos elementos da equipe multi-profissional, evitando que os conflitos pessoais tenham interferência negativa no trabalho;

5 - a estruturação de um programa de trabalho deve ser pratica desenvolvida pelos enfermeiros na administração de Unidades ou Serviços de Enfermagem desde os mais simples aos mais complexos;

6 - a execução das atividades e os resultados obtidos devem servir de estímulo e atualização do programa de trabalho desenvolvido no Serviço.

MENEZES, D. N. \& LOPES, M. C. S. Nursing service problems; experience in a work program structuration. Rev. Bras. Enf., Brasília, 39(2/3): 21-25, Apr./Sept., 1986.

\section{REFEREENCIAS BIBLIOGRÁFICAS}

1. ANGERAMI, E. L. S. \& ALMEIDA, M. C. P. De como o enfermeiro está inserido no seu "espaço". Rev. Bras. Enf., Brasília, 36 (2) : 123-9, abr./jun. 1983.

2. BARROS, S. M. P. F. \& ARAÚJO, M. J. S. Prática administrativa de enfermagem na rede de serviços de saúde. Rev. Bras. Enf., Brasilia, 36 (3/4): 255-9, jul./dez. 1983.

3. BRASIL. Ministério da Saúde. Modelo geral de enfermagem. Brasília, 1977.

4. Ministério da Previdência e Assistência Social. Manual de normas e procedimentos de enfermagem hospitalar. Brasilia, 1982.

5. DOURADO, H. G. A enfermeira e a institucionalização da profissão e de seu novo papel protissional. Rev. Bras. Enf., Brasília, 31 (3): 293-303, jul./set., 1978.

6. FERNANDES, J. D. Contribuicão da equipe multi-profissional nas ações de saúde - mito ou realidade? Rev. Bras. Enf., Brasilia, 34 (2): 175-81, abr./jun. 1981 . 